\title{
Evaluation of selected surface integrity parameters after machining of composite materials with natural reinforcement
}

\author{
J.Zajac ${ }^{1}$, F.Botko ${ }^{1}$, S.Radchenko ${ }^{1}$, P.Radič ${ }^{1}$, A. Bernat ${ }^{1}$, J.Roman ${ }^{1}$ and B. \\ Zajac $^{1}$
}

\begin{abstract}
Presented article is focused on machining of composite materials with natural reinforcement and evaluation of selected surface integrity parameters. Wood plastic composite or wood filed plastics, ensure high resistance to rot, due to mixture of plastic material with organic wood fibers. Main issue for machining of wood plastic composite is low specific weight and excellent ratio between density and rigidity. Experimental part is aimed to machining wood plastic composite and subsequently evaluation of machined surface quality which is dependent to parameters of machining.
\end{abstract}

Keywords: wood plastic composite, surface roughness, machining, cutting speed

\section{Introduction}

Presented article is focused on machining of composite materials with natural reinforcement and evaluation of selected surface integrity parameters. Nowadays composite materials are used to replace traditional materials. These new materials combine several materials with different attributes [1].

Development of wood plastic composites (WPC) started at the beginning of 80 's in twentieth century located in USA. Wood filled plastics are mixed and shaped using extruders. Many plastic materials, such as polyethylene, polypropylene and polyvinylchloride are used in production of WPC [3] [5] [7].

Nowadays is trend to machine all kinds of composite materials. Aim of his article is machining and evaluation of surface roughness parameters for material Megawood. Quality control in machining process is very important [2]. 


\section{Experimental procedure}

Description of experimental material is listed in table below (Tab. 1 .) Preparation of test samples consists of 3 steps :

Step 1: Cutting (band saw BOMAR ERGONOMIC 275.230 DG)- cutting to length $150 \mathrm{~mm}$,

Step 2 : Turning (lathe SUI 40)- turning of square profile to diameter 36 $\mathrm{mm}$, equipement: three jaw chunk, tail stock,

Step 3: final turning - turnig to final diameter with depth oéf cut ap=2,5 $\mathrm{mm}$.

Parameters of turning toll used for machining of experimental samples:

- $\quad$ rake angle on the back plane $\gamma p=30^{\circ}$

- $\quad$ side range $\alpha p=10^{\circ}$

- $\quad$ end cutting edge angle $\kappa r=45^{\circ}$

- nose radius $r \varepsilon=5 \mathrm{~mm}$

- $\quad$ tip angle $\varepsilon r=90^{\circ}$

- $\quad$ side relief angle $\gamma f=0^{\circ}$

Cooling fluid was not used due to high content of wood. Machining was performed with constant depth of cut ap $=2,5 \mathrm{~mm}$ and as variable parameters were set feed speed per revolution $\mathrm{f}$, revolutions per minute (RPM) and cutting speed [m.min-1].

\subsection{Topography of machined surface}

Topography of individual samples was scanned using optical profilemeter MicroProf ${ }^{\circledR}$ FRT (Fig. 4.). Measuring with optical spectrometer belongs to noncontact and nondestructive methods. Experimental sample is located on machines work table, which is moving rapidly, accurately and is controlled by microprocessor. Topography data can be obtained from surface areas. Optical profilemeter works with fixed focus (do not use autofocus technology) and data are obtained from each single point independently, which leads high speed of measuring process [6] [8]. 
Surface roughness parameter $\mathrm{Rz}$ was measured with nine repeats and subsequently arithmetical average was calculated for each sample. Graphical dependences of $\mathrm{Rz}$ on feed speed rate $\mathrm{f}$ and cutting speed vc were created. During machining process several flat cracks occurred on machined surface. Cracks were excluded from measuring process because were causing distortion of final values.

Figures (Fig.5., Fig.6.,Fig.7.) shows examples of scanned surface. Area of scanning was selected to $2 \times 2 \mathrm{~mm}$. Individual samples from B1 to B15 shows recognizable differences. Graphical dependence (fig. 9) illustrates change of surface roughness parameter Rz with increasing cutting speed.

Values of roughness parameters were obtained using software Gwyddion. Subsequently arithmetical averages were calculated and were created graphical dependences.

On following picture (Fig.5) can be observed scan of experimental sample B6 machined with parameters $\mathrm{f}=0,1 \mathrm{~mm}$ and $\mathrm{vc}=101,79 \mathrm{~m} \cdot \mathrm{min}^{-1}$. Dense grid is visible which is caused by low values of feed speed.

On following figure (fig.6) is example of experimental sample manufactured with feed speed per revolution $\mathrm{f}=0,3 \mathrm{~mm}$. In comparison with previous figure (Fig.5.) there are visible approximately three times less tool marks.

Experimental sample displayed on following figure (Fig .7.) was produced with highest pre-set of feed speed rate $(\mathrm{f}=0,61)$ used in this experiment. There can be clearly observed three tool markings on whole scanned area (feed speed rate was 0,61 and size of scanned area $2 \times 2 \mathrm{~mm}$ ).

\section{Conclusion and discussion}

Graphical dependence (Fig. 8) illustrates change of surface roughness parameter $\mathrm{Rz}$ with increasing cutting speed. Values of maximal surface roughness $\mathrm{Rz}$ are in the range from 11,31 $\mu \mathrm{m}$ (sample B1) to $13 \mu \mathrm{m}$ (sample B6). From graph is evident that for minimal cutting speed $v c=50,89$ m.min-1 values of Rz obtain decreasing trend for whole range of feed speed rates (from 0,1 to $0,61 \mathrm{~mm}$ ).

Similar trend can be observed for cutting speed $\mathrm{vc}=101,79 \mathrm{~m}$.min-1. For cuuting speed at maximal value ( $\mathrm{vc}=158,34 \mathrm{~m}$.min-1) values of maximal surface roughness $\mathrm{Rz}$ significantly increase for feed speed rate $\mathrm{f}=0,3 \mathrm{~mm}$ and afterwards decrease to value $14,85 \mu \mathrm{m}$ ( difference $4,02 \mu \mathrm{m}$ ).

Graphical dependence (fig. 9) represents influence of decreasing cutting speed $\mathrm{vc}$ on machined surface quality. For middle and maximal settings of feed speed rate curves obtain very similar course. Values of maximal surface roughness $\mathrm{Rz}$ slightly decrease for cutting speed 101,79 m.min-land afterwards rapidly increase for cutting speed 158,34 m.min-1. For minimal feed speed rate obtain curve convex characteristics with local maximum on cutting speed 101,79 m.min-1.

From theoretical point of view should with increasing of feed speed rate obtain surface quality decreasing trend. Vice versa increasing cutting speed should im- 
prove quality of machined surface. Machining of wood plastic composite paradoxically does not confirm this theoretical axiom. Courses of graphical dependences indicate that for non-homogenous materials are obtained variable surface qualities. This paradoxical situation is caused by fact, that composite materials have random distribution of individual components in every cross section.

\section{Acknowledgements.}

This paper has been elaborated in the framework of the project APVV $-15-0700$.

\section{References}

[1] Angelovič, M., 2016, Machining of composite material with natural reinforcement, diploma thesis, 61pages

[2] Hutyrová, Z., Zajac, J., Mital, D., Harničárová, M., Valíček, J., Evaluation of share material after turning of wood plastic composite, (2015) Proceedings - International Conference on Solar Energy and Building, ICSoEB 2015, art. no. 7244946, Chapter: Surname, A. (2010) Title of chapter. In Surname, C. [ed.], Title of Book (Publisher location: Publisher), ch. 3.

[3] J. Zajac, D. Mital, S. Radchenko, et al., Short-term Testing of Cutting Materials Using the Method of Interrupted Cut, in: S. Fabian, T. Krenicky (Eds.), Operation and Diagnostics of Machines and Production Systems Operational States II book series: Applied Mechanics and Materials, 2014, pp. 236-243.

[4] J. Zivcak, M. Petrik, R. Hudak, et al., Embedded Tensile Strenght Test Machine FM1000-An Upgrade of Measurement and Control, in: Z. Gosiewski, Z. Kulesza (Eds.), Mechatronic systems and materials III., Book Series: Solid State Phenomena, 2009, pp. 657-662.

[5] R. Cep,A. Janasek, J. Petru, et al., Surface Roughness after Machining and Influence of Feed Rate on Process,in: J. Kundrat, Z. Maros (Eds.), Precision Machining VII Book Series: Key Engineering Materials, 2014, pp. 341-347.

[6] J. Valicek, M. Drzik,T. Hryniewicz,Non-Contact Method for Surface Roughness Measurement After Machining, Measurement Science Review. 12 (2012) 184-188.

[7] Nourbakhsh, N., Ashori, A., Fundamental Studies on Wood-Plastic Composites: Effects of Fiber Concentration and Mixing Temperature on the Mechanical Properties of Poplar/PP Composite, Polymer Composites, Wiley InterScience, 2008, p. 569-573

[8] Kuo, P., Wang, S., Chen, J., Hsueh, H., Tsai, M., Effects of materials compositions on the mechanical properties of wood-plastic composites manufactured by injection molding, Materials and Design, 2009, edt. 30, p. 3489-3496 
Figure 1. Cutting of experimental samples on band saw

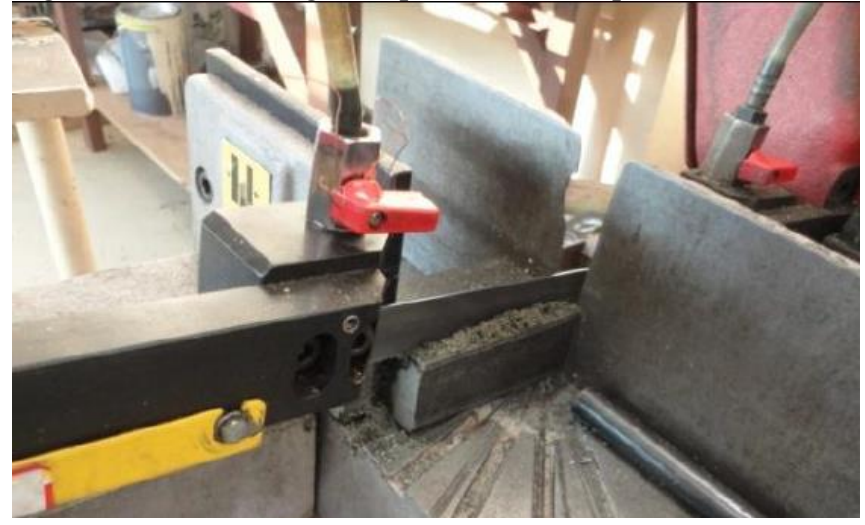

Figure 2. Turnig to baseline diameter

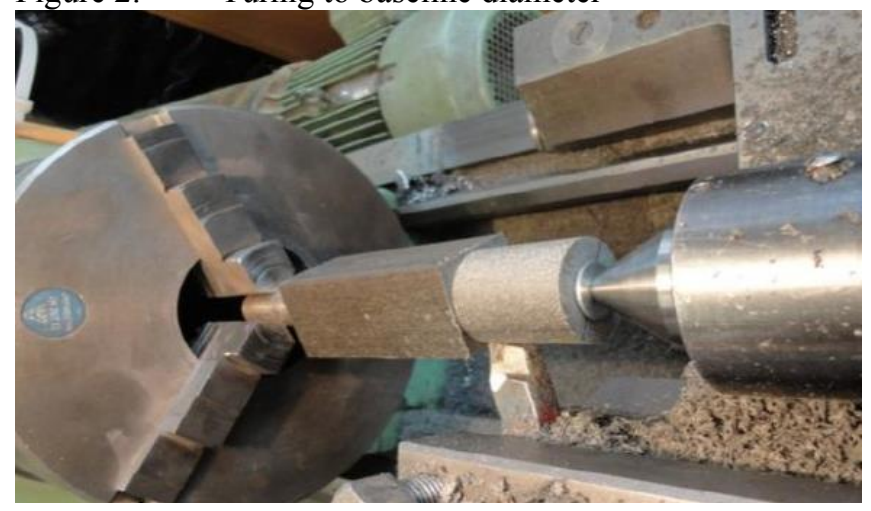

Figure 3. Final turnig ap=2,5mm

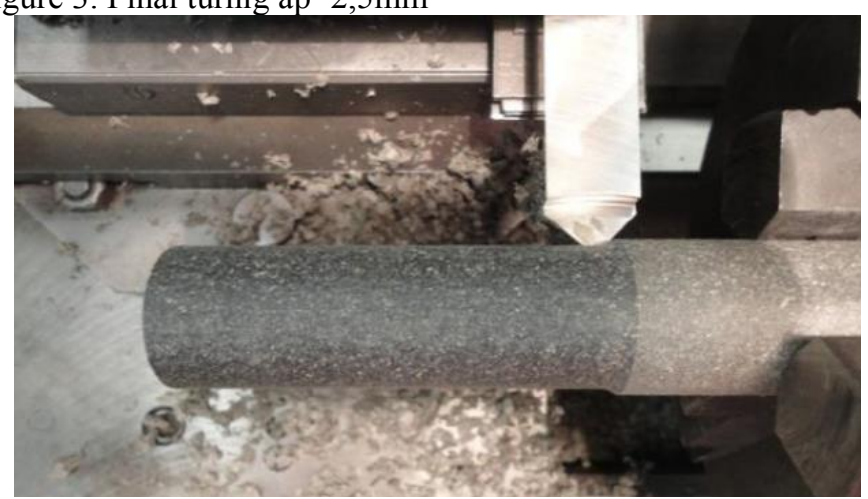


Figure 4. Optical profilemeter Micro Prof FRT

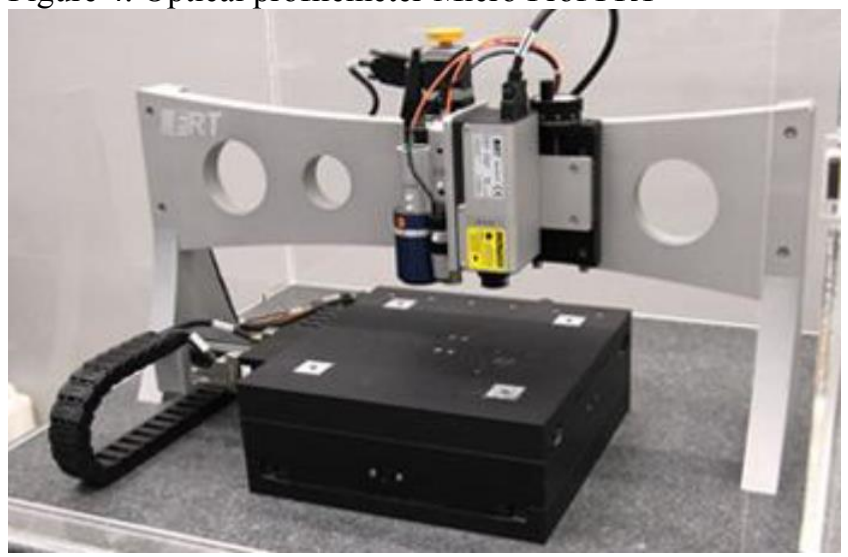

Figure 5. Experimental sample B6 $(\mathrm{f}=0,1 \mathrm{~mm})$

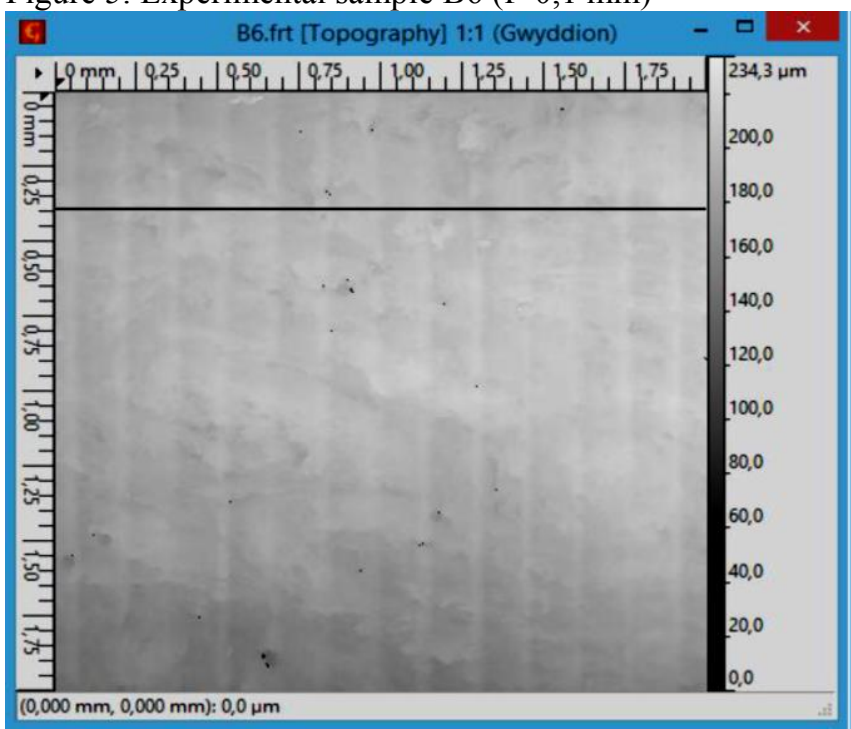


Figure 6. Experimental sample B8 ( $\mathrm{f}=0,3 \mathrm{~mm})$

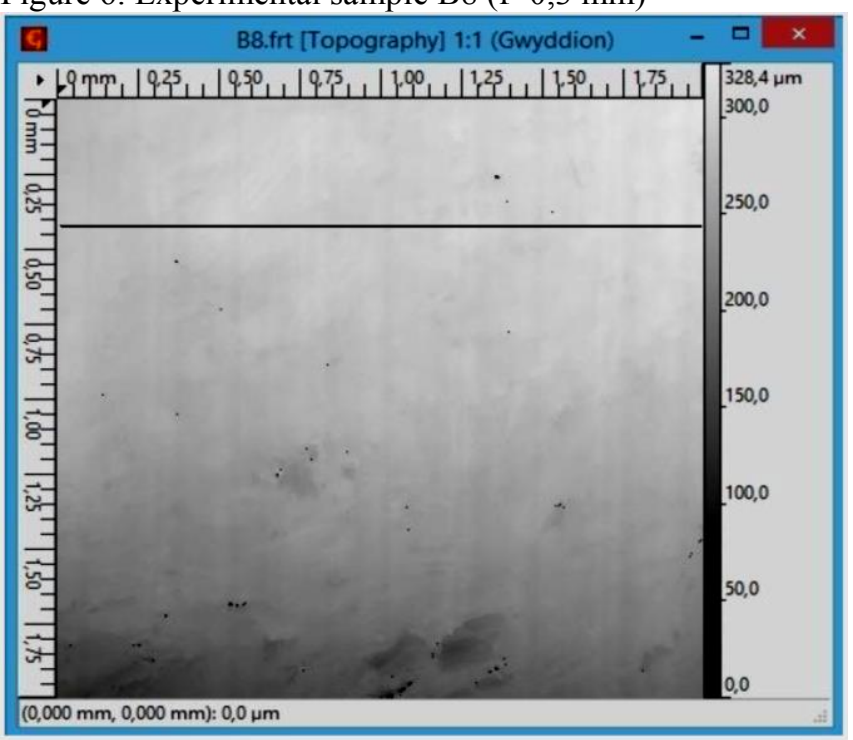

Figure 7. Experimental sample B6 $(\mathrm{f}=0,61 \mathrm{~mm})$

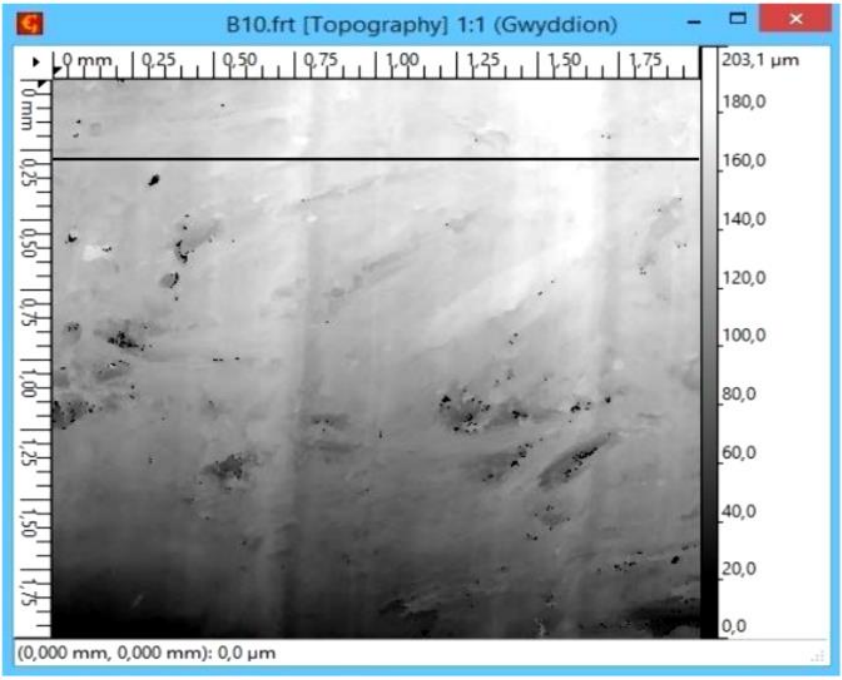


Figure 8. Graphical dependence $\mathrm{Rz}$ on $\mathrm{f}$

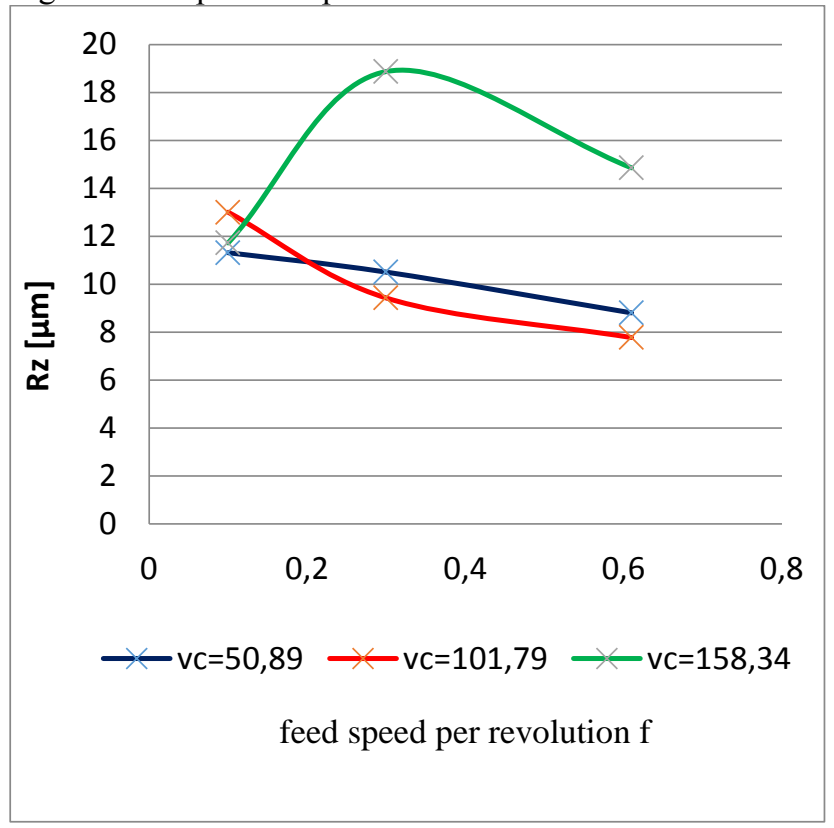

Figure 8. Graphical dependence $\mathrm{Rz}$ on vc

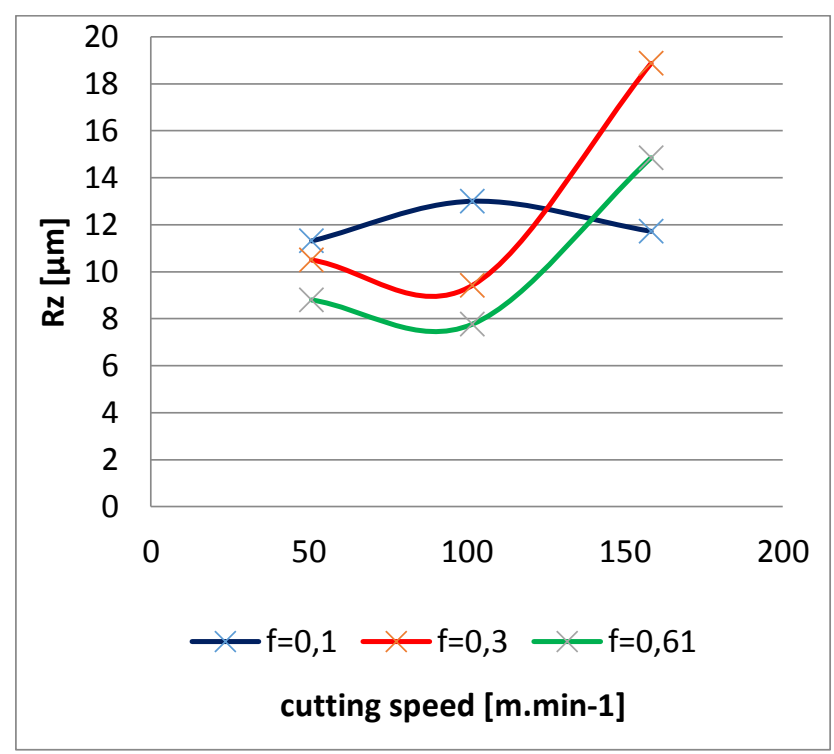


Table 1. Description of experimental material

\begin{tabular}{ll}
\hline Commercial name & Megawood \\
\hline Material & Wood plastic composite \\
Dimensions & $40 \times 60 \times 3600 \mathrm{~mm}$ \\
Color of material & Brown pigment \\
Matrix & HDPE \\
$\begin{array}{l}\text { Composition of wood } \\
\text { filling }\end{array}$ & $75 \%$ of wood + HDPE \\
Size of particles & From 420 $\mu \mathrm{m}(\operatorname{mesh} 35)$ \\
Stability & Decomposition at 180 \\
\hline
\end{tabular}

Table 2. Cutting conditions

\begin{tabular}{llll}
$\begin{array}{l}\text { Sample } \\
\text { marking }\end{array}$ & $\mathrm{f}[\mathrm{mm}]$ & $\mathrm{RPM}[\mathrm{min}-1]$ & $\mathrm{Vc}[\mathrm{m} . \mathrm{min}-1]$ \\
\hline B1 & 0.1 & 450 & 50,89 \\
B3 & 0,3 & 450 & 50,89 \\
B5 & 0,61 & 450 & 50,89 \\
B6 & 0,1 & 900 & 101,79 \\
B8 & 0,3 & 900 & 101,79 \\
B10 & 0,61 & 900 & 101,79 \\
B11 & 0,1 & 1400 & 158,34 \\
B13 & 0,3 & 1400 & 158,34 \\
B15 & 0,61 & 1400 & 158,34 \\
\hline
\end{tabular}

